\title{
A Study of the Deformation, Network, and Aging of Polyethylene Oxide Films by Infrared Spectroscopy and Calorimetric Measurements
}

\author{
Carl Bergeron, ${ }^{1}$ Etienne Perrier, ${ }^{2}$ Aymeric Potier, ${ }^{2}$ and Geneviève Delmas ${ }^{1}$ \\ ${ }^{1}$ Départment de Chimie, Université du Québec à Montréal, CP.888, Suc. Centre-Ville, Montreal, QC, Canada H3C 3P8 \\ ${ }^{2}$ IUT, University of Auvergne, 63001Clermont-Ferrand, France
}

Correspondence should be addressed to Carl Bergeron, carl.karine@videotron.ca

Received 22 July 2011; Revised 27 October 2011; Accepted 7 November 2011

Academic Editor: Karol Jackowski

Copyright (C) 2012 Carl Bergeron et al. This is an open access article distributed under the Creative Commons Attribution License, which permits unrestricted use, distribution, and reproduction in any medium, provided the original work is properly cited.

\begin{abstract}
The calorimetric and infrared (IR) spectroscopy measurements of polyethylene oxide (PEO) are used to evaluate the deformation and relaxation that films experience during a temperature cycle $\left(30^{\circ} \mathrm{C}-90^{\circ} \mathrm{C}-30^{\circ} \mathrm{C}\right)$. After melting, the intensity of some bands decreases by 10 to $70 \%$. During the temperature cycle, the $\mathrm{C}-\mathrm{O}$ band in the $1100 \mathrm{~cm}^{-1}$ region and the $\mathrm{C}-\mathrm{C}-\mathrm{O}$ deformation bands at 650 and $500 \mathrm{~cm}^{-1}$ show some new features. A network of cooperative oxygen-hydrogen interactions between the PEO chains form in films with special history, namely, in thermally treated films, in thin films prepared from gel forming solutions, and in thick films after aging. The interchain interaction network is suggested from the IR absorption bands in the 1200 and $900 \mathrm{~cm}^{-1}$ region and also from small bands at 1144 and $956 \mathrm{~cm}^{-1}$. The network seems absent or reduced in thin films. IR spectroscopy appears a sensitive technique to study chain conformations in PEO films and in other materials where order, disorder, and the formation of intermolecular interactions coexist.
\end{abstract}

\section{Introduction}

The physico-chemical properties of pure polyethylenoxide (PEO) such as crystallinity [1-3], thermal properties [2, 3], and morphology $[4,5]$ have been investigated. The polar and nonpolar parts of the PEO sequence give rise to a wide range of properties unknown to polyolefins. An intriguing property of PEO in dilute and very dilute solutions is the formation of stable clusters $[6,7]$. Nonequilibrium effects related to the polymer-solvent interactions have been studied [8]. Associations have been investigated by several techniques in order to understand the thermodynamics of their origin and obtain some insight into protein-water interactions [9]. The effect of shear on solutions and resulting degradation has been analysed [10].

The vibrational spectra of oriented PEO films have been measured $[11,12]$ and the positions of the bands were compared to those calculated. Structural models and comparison with the IR spectra of small molecules have suggested the assignments of the bands between 3000 and $400 \mathrm{~cm}^{-1}$ observed for the solid and for the melt. Ionic conductivity, effect of surface on conformations, and crystallinity have been investigated in PEO systems in fundamental and applied FTIR studies [13-16]. FTIR spectroscopy is used to study the specific interactions between the PEO chains and small molecules [13]. Chain-chain interactions in composites and chainion interactions leave a trace on the vibrational spectrum. They increase the parallel portion of the vibrations at the expanse of the perpendicular ones, especially in the CO band at $1115-1109 \mathrm{~cm}^{-1}$. Thin films of pure PEO and composites have been investigated by different techniques including IR spectroscopy. The effect of the adsorption on a solid surface like $\mathrm{KBr}$ or silicon substrates on the chain mobility was investigated through the intensity of bands specific to the crystal and the melt. Mobility is found to be reduced by the interaction of the PEO chains with the surface with consequence on the crystallization kinetics [14]. PEO crystallizes in a monoclinic cell, with the chain adopting a 7/2 helix but in a triclinic cell with a planar zigzag conformation when the sample is distorted. 
The interesting and wide-range properties of this polymer have been exploited in biological and pharmaceutical research. A variety of copolymers of PEO and polyolefins have been synthesized. PEO chains can be chemically linked to a variety of molecules (peptides, proteins, antibody fragments, and small molecules) and have been used for drug delivery $[15,16]$. Polymer partitioning is a key factor in the formation of biphasic systems and is of importance in the transport of active agents linked to PEO across cell membranes [15].

Stable associations and micelle formations are found in block copolymers (A-A) $)_{m}-(\mathrm{B}-\mathrm{B})_{n}$ with different polarities of the A-A and B-B groups. They have been observed surprisingly in random polyethylene-polypropylene copolymers, where the $-\mathrm{CH}_{2}-\mathrm{CH}_{2}-$ segments and the $-\mathrm{CH}\left(\mathrm{CH}_{3}\right)-\mathrm{CH}_{2}-$ segments are not polar [17]. A noncrystalline organization can grow in the absence of hydrogen bonds or other strong interactions to minimize free energy. Unexpected variation of the PEO IR spectra with film thickness and solvent history are reported below and in unpublished work in our group suggesting a certain similarity between the spontaneous organization of the PEO chains and those of the PE-PP polymer.

A standard strategy to investigate the phase content in polymers is to observe the effect of sample history (deformation, solvent, or thermal treatment) on the vibrational spectra or on the calorimetric trace. Distortion is usually achieved by an exterior mechanical force. In our laboratory, a T-ramp was used to deform the sample, events which can be followed by calorimetric measurements or by IR spectroscopy. A slow T-ramp is required to achieve and record sample deformation and to study the signals associated with the changes. The calorimetric trace displays not only the main peak of fusion, but also other signals which are found in the melt above $T_{m}$. This is a general feature [18-30] found on several polyolefins, for amylose and PEO (Appendix). The IR spectra reveal important changes due to the treatment, such as band displacement and change of intensity or position of the base-line related to the sample. For polyolefins, PET [31] and amylose [32,33], the integrated absorbance permits to determine (with some assumptions), the ordered, the disordered, and the strained fractions in a sample. For amylose pastes [32, 33], the combination of FTIR and calorimetric analyses illustrates conformation modifications with thermal treatment. Bands were tentatively assigned to simple and double helices, whose respective content was treatment dependent $[32,33]$. The sensitivity of some bands of the IR spectra to sample history has been investigated in mixtures of polymers [34]. Films with specific properties (such as high drawing ability and high resistance [22]) have been obtained, using as strategy of morphology modification, a gel whose chains are entangled. Indicators of network organization were found on the calorimetric signals and on the IR spectra $[18,30]$.

The possibility of finding the same concepts at work for PEO as for PE and amylose, through special thermal treatments and techniques like FTIR and calorimetry, seemed worthwhile and has been investigated [35-40]. Development of strain during aging or through phase changes initiated by treatment or by interactions with other molecules has been followed by ATR and FTIR spectroscopy. Results on pure PEO are likely to give useful information and trends in the mixtures prepared at different temperatures for biochemical and pharmaceutical research and applications. Due to its sensitivity to strain $[11,12]$, IR spectroscopy is a useful technique to follow deformation of PEO samples during the T-ramp.

In the present work, two strategies were used to change the sample morphology and follow their effect on the IR spectrum. A film prepared in standard conditions was submitted to a T-ramp covering a wide T interval and other films were obtained from entanglement-enriched solutions and analysed at RT as a function of aging time. This controlled preparation and treatment and the knowledge of spontaneous growth of a physical network can be of help for investigating the effect of $\mathrm{PEO}$ processing and aging on its in-use properties such as resistance to wear, brittleness, and permeability.

\section{Experimental}

2.1. Materials. PEO is from the Aldrich Company. The sample is characterized by MW $=10^{4}$. In order to prepare gels and network-rich films, solutions are made with a higher MW (Aldrich, $\mathrm{MW}=10^{6}$ ) or a higher concentration of the lower MW sample. The polymers used as received are kept in desiccators. The solvents are of chromatographic grade from Aldrich.

2.2. Calorimetry. Standard DSC measurements were performed on a Perkin Elmer DSC-7, calibrated with Indium. Slow calorimetry was done on a Setaram C80 calorimeter, as in our previous works $[18-30,32,33]$. Table 1 gives the characteristics of the calorimetric traces obtained with standard conditions and with slow calorimetry [36, 39]. A calorimetric trace using a slow T-ramp $(3 \mathrm{~K} / \mathrm{h})$ is given in the Appendix.

2.3. FTIR. The FTIR instrument is a Bomen spectrometer (MB series, Bomen Inc, Canada) used in transmission mode. The spectra were recorded after 50 scans at a resolution of $1 \mathrm{~cm}^{-1}$. The IR chamber is flushed by dry nitrogen during the measurements.

2.3.1. Spectra as a Function of Temperature. The IR spectra were taken using a home-made oven $[28,30,32,33]$. The sample and a thin thermocouple are placed between two $\mathrm{KBr}$ disks and maintained with Teflon tape in a well isolated oven. The heating wires of the oven and the thermocouple are plugged into a precise temperature controller. The temperature cycle is $30^{\circ} \mathrm{C}-90^{\circ} \mathrm{C}-30^{\circ} \mathrm{C}$. The heating ramp includes a step of $6 \mathrm{~K}$ at $0.5 \mathrm{~K} / \mathrm{min}$, followed by a one-minute isotherm and repeated until the maximum temperature. The cooling rate is $1.7-0.7 \mathrm{~K} / \mathrm{min}$ between 90 and $60^{\circ} \mathrm{C}$ and $0.2 \mathrm{~K} / \mathrm{min}$ around $T_{c}$. An IR spectrum was taken every $13 \mathrm{~min}$. 
TABLE 1: Characteristics of the melting traces of the PEO sample in different conditions.

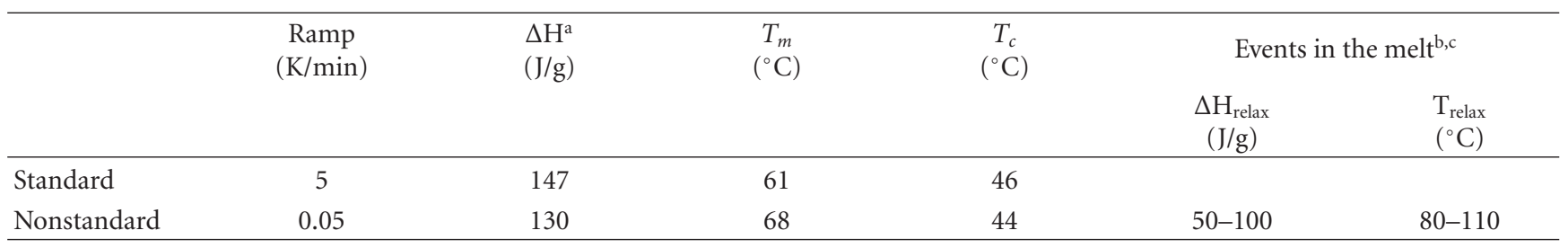

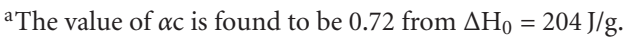

b The value of $\Delta \mathrm{H}_{\text {relax }}$ and the range of $\mathrm{T}_{\text {relax }}$ are sensitive to the conditions [22-30, 36, 37].

${ }^{\mathrm{c}}$ The signal in the melt is endothermic for a deformation and exothermic for a relaxation.

2.3.2. Baseline Subtraction. The wires emit IR signals, which vary with the heating power. The signal from the cell has been measured in a blank experiment at the same rate of heating and cooling as in the experiment. It was subtracted from the data obtained with the sample at every temperature $[29,32$, $36,39]$.

2.3.3. Sample Preparation. The film submitted to the T-ramp is prepared as follows: the dissolution of the polymer in toluene with a $0.5 \%$ concentration is assisted by sonication during $20 \mathrm{~min}$. The container is surrounded by iced water to avoid a rise of temperature. The power of the sonicator is carefully adjusted by trial and error $[36,39]$ to avoid sample degradation. The constancy of the sample MW is checked by measuring the solution viscosity. After solvent evaporation at RT, the film, left to dry during two days, is placed between two KBr plates held by Teflon tape. The treatment of this film called thermally treated or (Therm-T) consists of a T-ramp, starting at $30^{\circ} \mathrm{C}$ up to the maximum temperature $\left(90^{\circ} \mathrm{C}\right)$ and cooling to RT. The film has a thickness of $15 \mu \mathrm{m}$. There is no trace of oxidative degradation on the IR spectra of Therm-T film after the T-cycle.

Free standing films: for comparison with Therm- $T$, free standing films of different history are prepared and analyzed at RT. The film (Reference) is prepared from a $1 \%$ solution in toluene. Dissolution at $40^{\circ} \mathrm{C}$ is assisted by a magnetic stirrer during two hours. In order to minimize the strain, evaporation is performed at $4^{\circ} \mathrm{C}$. Reference is a film, whose IR spectrum seems to have reached equilibrium (at the time of the analysis). The other free-standing films are obtained from solutions enriched in entanglements. Solvent evaporation is made at RT.

2.3.4. Aging. The films are analyzed usually two days after the solvent has evaporated. The thicker films are analyzed again three days after taking the first spectrum and in some cases after seven or more days.

2.3.5. Change in Chain Orientation and Band Intensity Variation at $T_{m}$. Since PEO repetitive unit contains a polar bond, chain reorganization is likely to affect the vibrational energies of the bonds. The average orientation of the bonds in the chains from the crystal to the melt will be modified and consequently, the IR band position and its maximum intensity will be affected. The terms parallel or perpendicular represent the direction of the transition dipole moments, which are parallel and perpendicular to the helical axes of PEO. These terms are satisfactory to describe changes in the solid submitted to different histories or those prepared in different solvents [35]. The perpendicular bands are also called helical bands and the parallel bands are those associated with a transplanar zigzag conformation. The latter is present in deformed samples or when the chains interact with others [34] or with ions [13]. An improved intramolecular interaction between the $\mathrm{CH}_{2}$ segments and the oxygen atoms was, according to P. J. Flory earlier, at the origin of the helical conformation of the PEO chains. However, the intermolecular interaction between several $\mathrm{CH}_{2}$ groups and several oxygen atoms of two different chains is more feasible for chains in the zigzag conformation. The conformation will change from helix to zigzag to minimize the free energy engaged in interchain association.

2.3.6. Change in the Band Position. For PE, reduced cohesion between the chains in the melt shifts some bands towards lower energies $[29,30]$. The doublet of the $\mathrm{CH}_{2}$ rocking is at $720-730 \mathrm{~cm}^{-1}$. A new band is observed at $712-715 \mathrm{~cm}^{-1}$ in the nascent materials where the chains are strained. In suitable conditions, the deformed crystals change from the orthorhombic to monoclinic modification. In PEO, the change of the position of the maximum intensity is due mainly to changes of orientation. New bands are formed in $\mathrm{M}$, so that there is an unavoidable ambiguity in comparing small bands in $\mathrm{C}$ and $\mathrm{M}$.

The polarized IR spectra of strongly oriented PEO samples [11] enriched in parallel bands by deformation are informative. In Table 2, the comparison of the different bands is made for a qualitative evaluation, using $\varepsilon$ for short $[11,12]$. The values of the extinction coefficients are not given explicitly, only the bands and the maximum absorbance with different light orientations are shown. For the doublets (1359$1342,1242-1235$, and $963-947 \mathrm{~cm}^{-1}$ ) and for the 1280,1260 and $844 \mathrm{~cm}^{-1}$ bands, $\varepsilon$ is reported to change greatly with change of light polarization in the deformed samples (by a factor of 2 and 3). On the other hand, the parallel and perpendicular bands present, in the $-\mathrm{CH}_{2}$ stretching region and the $\mathrm{CO}$ stretching region, have similar values of $\varepsilon$, so one can expect minimum change at $T_{m}$. Assuming that the trends observed for the highly stretched sample remain valid for Therm- $\mathrm{T}$, one can expect that the change of absorbance, $\Delta$ (Abs), at $T_{m}$ will depend on the region of the spectrum. The data of the last row of Table 3 which lists the changes of 
TABLE 2: Relative values of the extinction coefficient, $\varepsilon$, for orientation-sensitive bands of PEO [11, 12].

\begin{tabular}{|c|c|c|}
\hline CH stretching 3000-2650 & Overlap $\|$ and $\perp$ vibrations & $\varepsilon \| \approx \varepsilon \perp$ \\
\hline $\mathrm{CH}$ bending $1500-1400$ & 1470: \| 1463: $\perp$ & $\varepsilon \| \approx \varepsilon \perp$ \\
\hline $\mathrm{CH}_{2}$ wagging/twisting & 1343: || 1359: $\perp$ & $\varepsilon \|>\varepsilon \perp$ \\
\hline $\mathrm{CH}_{2}$ wagging/twisting & $1280 \perp$ & $\varepsilon \|<\varepsilon \perp$ \\
\hline $\mathrm{CH}_{2}$, CO rocking/stretching & 1241: $\| 1235 \perp$ & $\varepsilon \|>\varepsilon \perp$ \\
\hline $\mathrm{CH}_{2}, \mathrm{CO}$ rocking/stretching & Overlap $\|$ and $\perp$ 1200-990 & $\varepsilon \| \approx \varepsilon \perp$ \\
\hline $\mathrm{CH}_{2}$ rocking $\mathrm{CO}$ stretching & $1060 \perp$ & $\varepsilon \|<\varepsilon \perp$ \\
\hline $\mathrm{CH}_{2}$ rocking $\mathrm{CO}$ stretching & 963: \| 947: $\perp$ & $\varepsilon \|>\varepsilon \perp$ \\
\hline $\mathrm{CO} / \mathrm{CH}_{2}$ rocking/stretching & 844: $\perp$ & $\varepsilon \|<\varepsilon \perp$ \\
\hline
\end{tabular}

TABLE 3: Variation of the standard integrated absorbance between $\mathrm{C}$ and $\mathrm{M}^{\mathrm{a}}$ for two large regions and for a doublet ${ }^{\mathrm{c}}$.

\begin{tabular}{|c|c|c|c|c|c|c|c|c|c|}
\hline & \multicolumn{3}{|c|}{$3000-2640\left(\mathrm{~cm}^{-1}\right)$} & \multicolumn{3}{|c|}{$1500-770\left(\mathrm{~cm}^{-1}\right)$} & \multicolumn{3}{|c|}{$1000-900\left(\mathrm{~cm}^{-1}\right)$} \\
\hline & Std $\mathrm{Abs}^{\mathrm{a}}$ & $\operatorname{Max} \mathrm{Abs}^{\mathrm{b}}$ & $\begin{array}{l}\text { Band position } \\
\qquad\left(\mathrm{cm}^{-1}\right)\end{array}$ & Std Abs & $\operatorname{Max} \mathrm{Abs}^{\mathrm{b}}$ & $\begin{array}{l}\text { Band position } \\
\left(\mathrm{cm}^{-1}\right)\end{array}$ & Std. $A b s^{c}$ & Max Abs. & $\begin{array}{c}\text { Band position } \\
\left(\mathrm{cm}^{-1}\right)\end{array}$ \\
\hline $\mathrm{C}$ & 78.3 & 0.92 & 2884 & 139 & 1.55 & 1114 & $7.7-7.0$ & $0.46-0.40$ & $963-947$ \\
\hline M & 72.6 & 0.72 & 2861 & 131 & 1.05 & 1109 & 3.5 & 0.25 & $991-948$ \\
\hline$\%^{c}$ & -9 & -25 & & -6 & -40 & & -70 & $-(10-45)$ & \\
\hline
\end{tabular}

${ }^{a}$ Using the standard method.

${ }^{b}$ From the spectra at $66^{\circ} \mathrm{C}$ on heating, $\mathrm{M}$, and $30^{\circ} \mathrm{C}$ on cooling, $\mathrm{C}$.

${ }^{\mathrm{c}}$ Bands are displaced from $\mathrm{C}$ to $\mathrm{M}$. Using nonstandard absorbance including NDA, the change is smaller.

integrated absorbance at $T_{m}$ for different regions are consistent with this assumption.

2.3.7. Integrated Absorbance. The maximum absorbance of a band $\left(\right.$ at $\left.\nu_{i}\right)$ is widely used as an analytical tool to measure the concentration of a molecule present in a material containing a bond vibrating at a specific energy $\left(\nu_{i}\right)$. Most of the studies have used relative intensities rather than absolute intensities because the intensities depend on many factors, some of which are difficult to control. However, it was found that in $\mathrm{PE}$ films prepared in controlled conditions, absorbance could be directly related to the sample thickness. A reliable extinction coefficient, $\varepsilon$, was obtained through the analysis of films of different thickness but the same history [26, 29, 35-40]. The value of $\varepsilon$ is dependant on the film history. When the morphology of the sample and not its chemical composition is of interest, the integrated absorbance is to be preferred to the maximum absorbance, because it takes into account the change of band-shape and the possible displacement of bands associated with the sample history. The extinction coefficient, $\varepsilon$, calculated by dividing the integrated absorbance by the film thickness has the unit of $\left(\mathrm{cm}^{-1} \mu \mathrm{m}^{-1}\right)$.

\subsubsection{Absorbance, Standard, and Nonstandard: Nondifferenti-} ated Absorbance (NDA). The IR spectra of polymers and gels present a feature which does not exist for small molecules. There is a nondifferentiated absorbance (NDA) which is situated between the base line and the spectrum. It corresponds to the different conformations which exist in the sample, the bonds of which have about the same frequency, the same energy and the same probability of occurrence. NDA is found mostly between 1200 and $900 \mathrm{~cm}^{-1}$ in the PEO spectra. The size of NDA gives some information on the amorphous or gel content of the sample. NDA has not received much attention in the IR literature, although it is sizeable in samples with a low crystallinity.

The evaluation of the standard integrated absorbance between $v_{1}$ and $v_{2}$ is straightforward, when one uses as base line a straight line between the absorbance $\mathrm{A}\left(\nu_{1}\right)$ and $\mathrm{A}\left(\nu_{2}\right)$ on the trace. To evaluate the nonstandard integrated absorbance, one chooses as base line, a horizontal line starting at for example $1200 \mathrm{~cm}^{-1}$ and going to the bond frequency of interest for instance $900 \mathrm{~cm}^{-1}$. The difference between $\mathrm{A}$ $\left(900 \mathrm{~cm}^{-1}\right)$ and the point on the base line at $900 \mathrm{~cm}^{-1}$ gives a qualitative information on the NDA at $900 \mathrm{~cm}^{-1}$. Alternatively, the difference of integrated absorbance between the nonstandard absorbance using two points A $\left(1200 \mathrm{~cm}^{-1}\right)$ and Baseline $\left(900 \mathrm{~cm}^{-1}\right)$ and the standard value is a measurement of the NDA in that region.

In PEO samples, the standard absorbance does not vary much at $T_{m}$ when measured between two distant values of the wavenumber as reported in Table 3. It is the proportion of nondifferentiated absorbance (NDA) over the total absorbance which changes at $T_{m}$. The value of $\Delta(\mathrm{Abs})$ between the solid and the melt is unambiguous for the $-\mathrm{CH}_{2}$ stretching band, because this band has no NDA but for other bands and doublets with a smaller intensity, the value of $\Delta$ (Abs) at $T_{m}$ or $T_{c}$ depends on the limits of the integration chosen.

Free-standing samples have been analyzed at different light polarization. The spectra of the equilibrium films were not different with the light orientation at $90^{\circ}, 0^{\circ}, 45^{\circ}$, but the maxima of the bands of thick films in the process of aging is displaced when changing the light polarization.

2.3.9. Film Thickness. The film thickness is measured with a calliper. In a series of films in equilibrium of different 




(a)

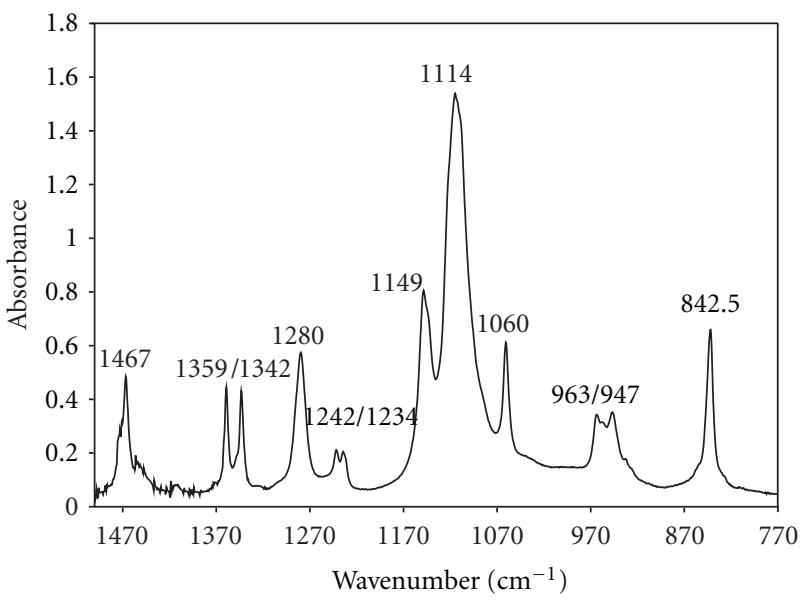

(c)

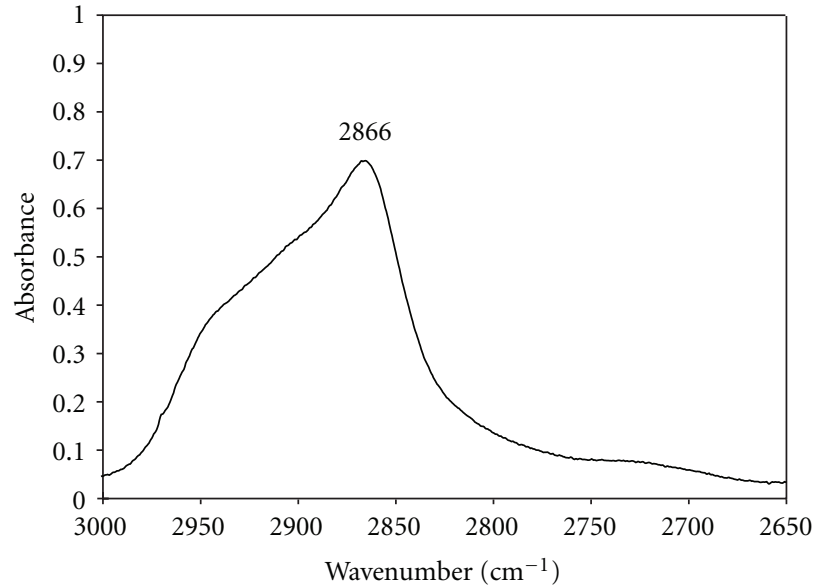

(b)



(d)

Figure 1: Spectrum between 3000 and $2660 \mathrm{~cm}^{-1}$. (a) Sample in the solid state at $30^{\circ} \mathrm{C}$ on cooling at the end the T-cycle; (b) sample in the liquid state. Spectrum between 1500 and $770 \mathrm{~cm}^{-1}$; (c) sample in the solid sample at $30^{\circ} \mathrm{C}$ on cooling at the end the T-cycle; (d) sample in the liquid state.

thickness but the same history, the integrated absorbance of the $-\mathrm{CH}_{2}$ stretching group is found to vary regularly with thickness so that a value of $\varepsilon=5\left(\mathrm{~cm}^{-1} \mu \mathrm{m}^{-1}\right)$ [35] was obtained. For very thin films whose thickness is not precise when measured with a calliper, their thickness is measured through $\varepsilon$ and the integrated absorbance of the $\mathrm{CH}_{2}$ stretching of their spectrum. In films in the process of aging, in which this region is not stable, another crystalline band relatively insensitive to conformations is used. The two films which will be compared in detail are Therm- $\mathrm{T}(15.0 \mu \mathrm{m})$ and Reference $(11.5 \mu \mathrm{m})$.

2.3.10. IR and Network Tracer. The presence of a network in a material is revealed by its IR spectrum if the junctions are made of interacting hydrogen bonds. The frequency of the $\mathrm{OH}$ bond is lower than in a material with free $\mathrm{OH}$ bonds. In systems where the $-\mathrm{CH}_{2}-\mathrm{O}-\mathrm{CH}_{2}$ segment is involved in a cooperative interaction with segments of another chain, one observes also a shift in the main peak of the CO. However, the difference of bond energy between the oxygen atoms which are part of the interaction and outside it is likely to be small. Consequently, only small differences of band position are expected and overlapping of bands composing the $\mathrm{CO}$ vibrations is likely to take place.

\section{Results and Discussion}

The vibrational spectra presented in this work focus on two subjects. The first is related to the changes in the IR spectra at melting or just before melting (Figures 1 and 2) and the observation of indicators of tension inside the sample during the ramp cycle, especially in the $1100-1090 \mathrm{~cm}^{-1}$ (Figure 3) and the $650-500 \mathrm{~cm}^{-1}$ region (Figures 4-5). The second part will focus on the observation of indicators of network organization at RT. Network-enriched films have been prepared and the results are compared to those observed in non-enriched samples such as a thin sample made from a dilute solution named Reference (Figures 6 and 7). While looking at the spectra of other films which would be similar to Reference albeit thicker, it was found that the thicker films cannot be 




(a)



(b)

FIgURE 2: Transition spectra at $60^{\circ} \mathrm{C}$ : The two regions show more bands than those observed in the solid and the melt (Figure 1(b)). (a) The $1400-1200 \mathrm{~cm}^{-1}$ interval (with eight bands). (b) The 1070-875 $\mathrm{cm}^{-1}$ interval (with six bands). Note the small band at $956 \mathrm{~cm}^{-1}$.

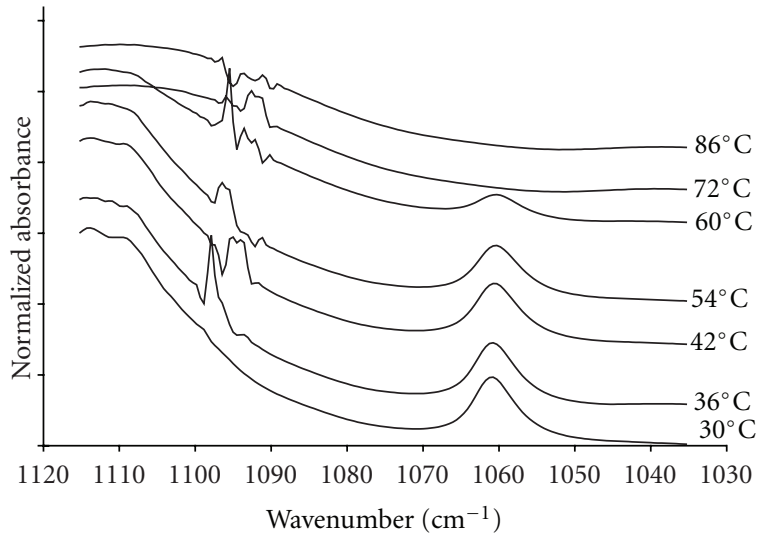

Figure 3: Spectra in the $1120-1100 \mathrm{~cm}^{-1}$ region at different temperatures going from the solid to the liquid phase. The $\mathrm{C}-\mathrm{C}$ twisting bands on the $1090-1100 \mathrm{~cm}^{-1}$ interval are seen as indicators of deformation in the T-ramp. Deformation starts after the beginning of the ramp (between 30 and $36^{\circ} \mathrm{C}$ ) and continues more than $25 \mathrm{~K}$ in the melt.

used without caution, since they reach their equilibrium conformation much slower. Figure $8(\mathrm{a}-\mathrm{d})$ gives an example of nonequilibrium thick films.

3.1. Melting. Melting changes considerably the absorption in the $1500-770 \mathrm{~cm}^{-1}$ region as reported earlier [12]. The bands associated with crystallinity, namely, the $-\mathrm{CH}_{2}$ bending $\left(1467 \mathrm{~cm}^{-1}\right)$, the $-\mathrm{CH}_{2}-\mathrm{CO}$ rocking/stretching $\left(843 \mathrm{~cm}^{-1}\right)$ and the band at $1060 \mathrm{~cm}^{-1}$ are no longer present or are reduced and displaced. The fine structure of several of the doublets is replaced by a large band and the $\mathrm{CO}$ band is wider and its maximum displaced $\left(1109 \mathrm{~cm}^{-1}\right)$.

In the $-\mathrm{CH}_{2}$ stretching and the $\mathrm{CO}$ regions (Table 3 ), the positions of the maximum intensity are seen to be shifted upon melting from $2883 \mathrm{~cm}^{-1}$ to $2861 \mathrm{~cm}^{-1}$ and from 1114 to $1109 \mathrm{~cm}^{-1}$. The integrated intensity is reduced (columns 1 and 4 ) by less than $10 \%$ for the two vibrations. For these two groups of vibration modes, the value of $\varepsilon \|$ is similar to that of $\varepsilon_{\perp}$. The band maximum intensity is reduced but the band is wider, keeping the integrated intensity at about the same value. The increased width indicates a larger range of conformations. Note that the values given for the $1500-770 \mathrm{~cm}^{-1}$ region cover also the $-\mathrm{CH}_{2}$ bending, twisting and wagging vibration modes. The change for the $\mathrm{CO}$ peak, not reported in Table 3, is the same $(-5 \%)$ as the $(-6 \%)$ given for the larger interval because the contribution of the small peaks is small (and $\varepsilon \|$ and $\varepsilon_{\perp}$ have different magnitudes). The intensity of the doublet (at 963-947 $\mathrm{cm}^{-1}$ ) associated with the $\mathrm{CH}_{2}$ rocking/CO stretching vibration is reduced by $70 \%$. The two peaks at 963 and $947 \mathrm{~cm}^{-1}$ are replaced by flattened bands at 991 and $948 \mathrm{~cm}^{-1}$ in the melt.

The moderate change of intensity of the two large bands of PEO at $T_{m}$ compared to the larger variation observed in $\mathrm{PE}$ is likely a consequence of the rather more disordered morphology of solid PEO. The density of a solid is usually a good indicator of the sample order. The density of $\mathrm{PE}$ is reduced by $20 \%$ at $T_{m}$, while the density of PEO is not very affected by melting.

The gradual change of the sample organization can be followed due to the slow T-ramp, better in some regions than in others. Melting is a slow process in the ramp conditions. For example, the maximum intensity of the $-\mathrm{CH}_{2}$ stretching band is at $2883 \mathrm{~cm}^{-1}$ at $56-60^{\circ} \mathrm{C}, 2875 \mathrm{~cm}^{-1}$ at $66^{\circ} \mathrm{C}$, and at $2866 \mathrm{~cm}^{-1}$ at $72^{\circ} \mathrm{C}$. Figure 2 shows the spectrum in two different regions around $T_{m}$. Due to the slow motion of the chains, bands specific to $\mathrm{C}$ and $\mathrm{M}$ can be observed in this transition spectrum at $60^{\circ} \mathrm{C}$. In Figure $2(\mathrm{a})$, the doublet at $1360-1343 \mathrm{~cm}^{-1}$ and the band at $1280 \mathrm{~cm}^{-1}$ of $C$ are still very present, while the parallel bands at $1296,1251 \mathrm{~cm}^{-1}$ of $\mathrm{M}$ have started to grow. In Figure 2(b), the crystalline band at $1060 \mathrm{~cm}^{-1}$ and the doublet at $963-947 \mathrm{~cm}^{-1}$ coexist with the $\mathrm{M}$ bands at $1039 \mathrm{~cm}^{-1}$ and $991 \mathrm{~cm}^{-1}$. The two spectra in 


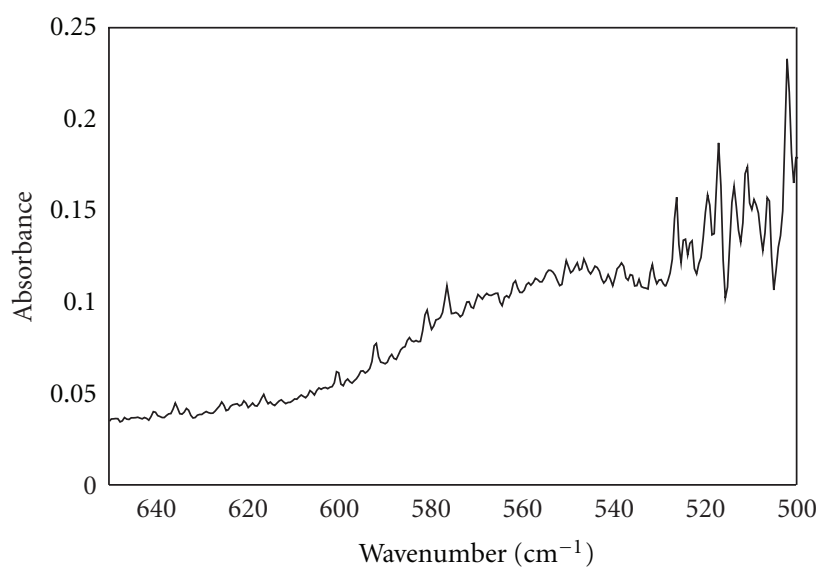

(a)

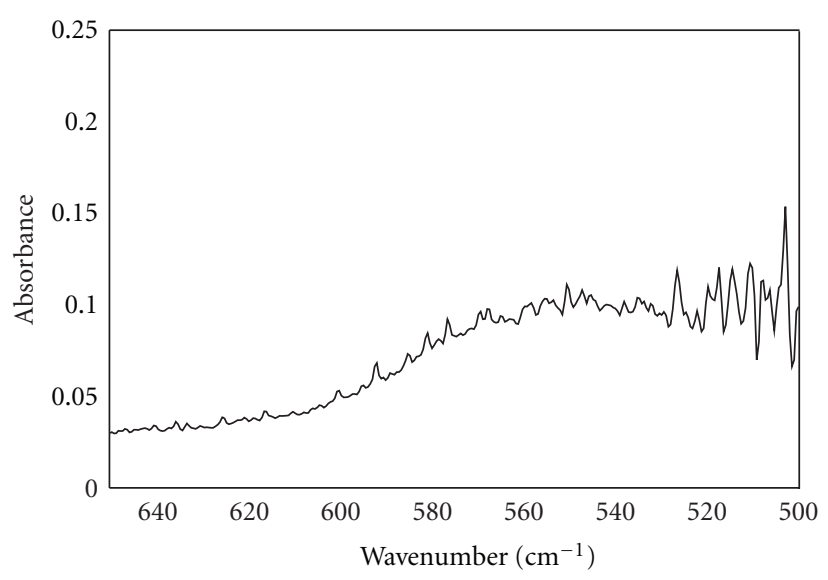

(b)

Figure 4: Spectra of Therm-T in the melt between 650 and $500 \mathrm{~cm}^{-1}$, (a) in the ascending ramp at $90^{\circ} \mathrm{C}$ and (b) in the descending ramp before crystallisation.

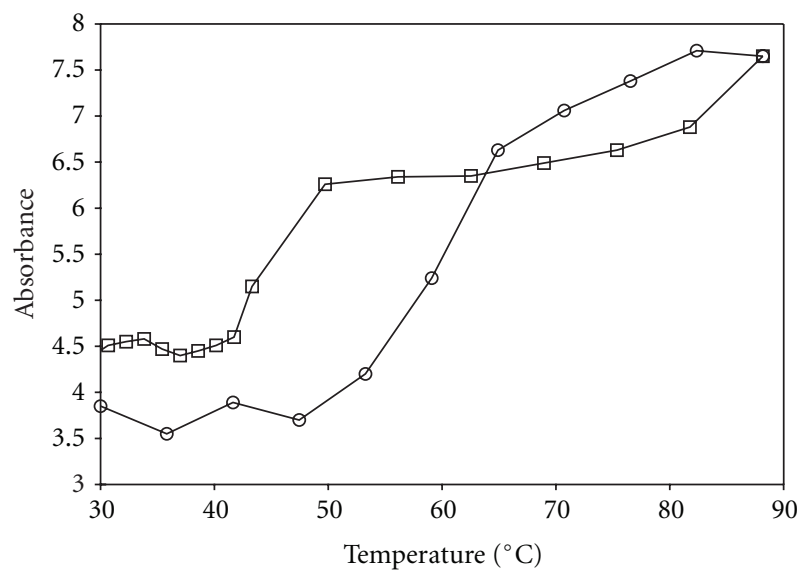

Figure 5: Spectra of Therm-T: variation as a function of $\mathrm{T}$ of the integrated nonstandard absorbance in the $\mathrm{C}-\mathrm{C}-\mathrm{O}$ bending region $\left(650-500 \mathrm{~cm}^{-1}\right)$. Heating $(\bigcirc)$ and cooling $(\square)$ ramp. The integrated absorbance at $30^{\circ} \mathrm{C}$ for the nontreated sample (Reference) is not shown on Figure 5 but is found lower (2.5) than that observed in Therm- $\mathrm{T}$ at the beginning of the T-ramp (3.8).

Figure 2 suggest that the value of the free energy of the conformations associated with these bands is rather similar over a range of temperature. Around $T_{m}$, the presence of polar groups along the chains in PEO maintains energetically favourable interchain interactions both in the solid and the melt phases. The relaxation time of the long chains has been investigated by different techniques in polystyrene [41]. The movement of the chains followed by slow calorimetry (Appendix) in the melt of PE and PEO was better understood through the results found on amorphous polystyrene.

3.2. Strain Building. Features in two regions of the IR spectra during the T-ramp investigation can be associated with deformation. These are seen in the CO stretching band

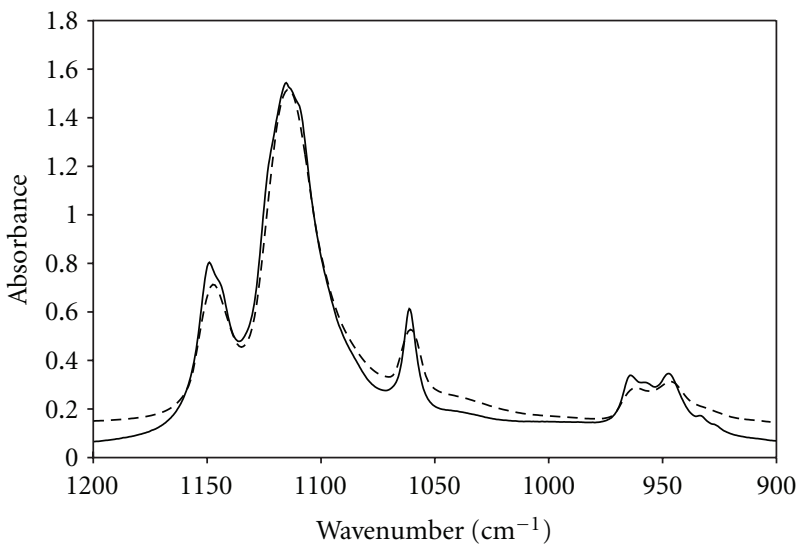

Figure 6: Tracers of network organization at $1144 \mathrm{~cm}^{-1}$ and $956 \mathrm{~cm}^{-1}$ and sample history, seen in Therm-T (solid line) but not apparent in Reference (dotted line).

(1200-1000 $\mathrm{cm}^{-1}$ ) and in the $\mathrm{C}-\mathrm{C}-\mathrm{O}$ bending region (650$\left.500 \mathrm{~cm}^{-1}\right)$. They will be discussed below.

3.3. CO Stretching Vibration at $1100-1090 \mathrm{~cm}^{-1}$. The low frequency side of the $\mathrm{CO}$ band is presented in Figure 3. The different traces shown between 1120 and $1030 \mathrm{~cm}^{-1}$ are a selection of IR spectra at different temperatures in the ascending ramp. The spectrum at $30^{\circ} \mathrm{C}$ shows only the perpendicular band at $1060 \mathrm{~cm}^{-1}$. Above $60^{\circ} \mathrm{C}$, this band disappears but returns as expected on crystallization. The spectra above $30^{\circ} \mathrm{C}$ show new signals between 1090 and $1100 \mathrm{~cm}^{-1}$, which vary in position, shape, and intensity. This is a characteristic associated with the superposition of several events, which can be interpreted as follows. When the T-ramp starts, the polymer is submitted to a strain, which continues until the temperature reaches its maximum at $90^{\circ} \mathrm{C}$. The events in the calorimetric trace (Appendix) show that other movements occur at the same time. Relaxation of parts of the stressed 


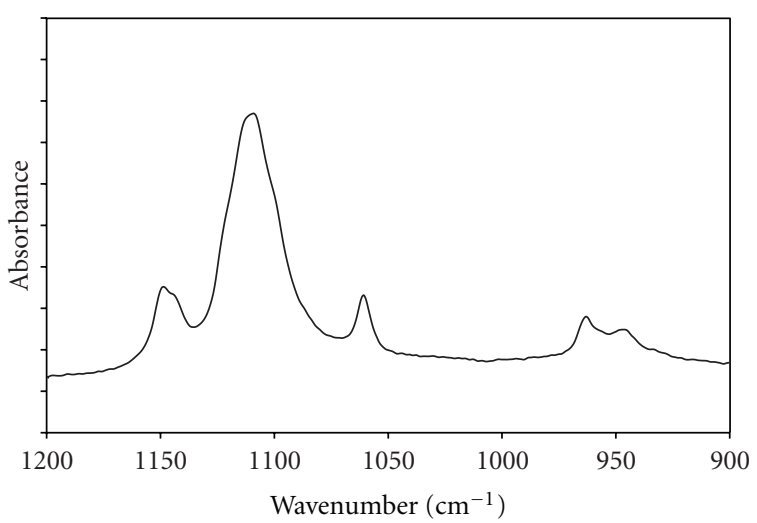

(a)

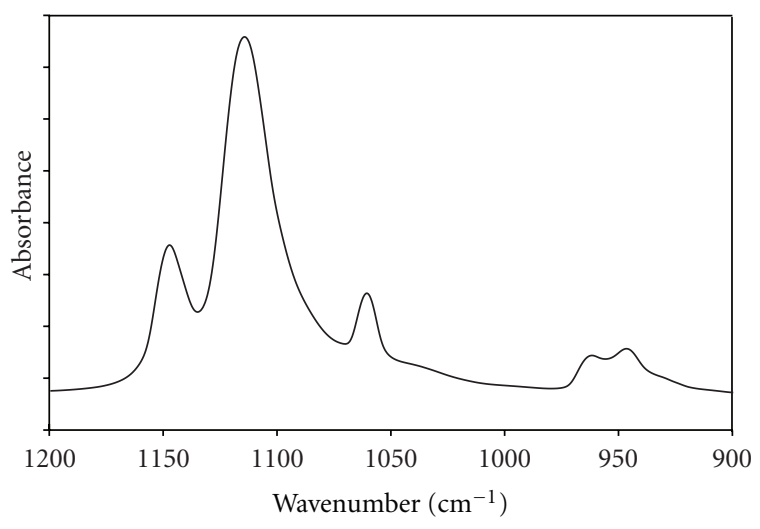

(b)

FIgURE 7: Tracers of network organization at $1144 \mathrm{~cm}^{-1}$ and $956 \mathrm{~cm}^{-1}$ and sample history: (a) thin film prepared from a gel (2.3 $\left.\mu \mathrm{m}\right)$; (b) therm- $\mathrm{T}$, the transition spectrum at $60^{\circ} \mathrm{C}(15 \mu \mathrm{m})$.

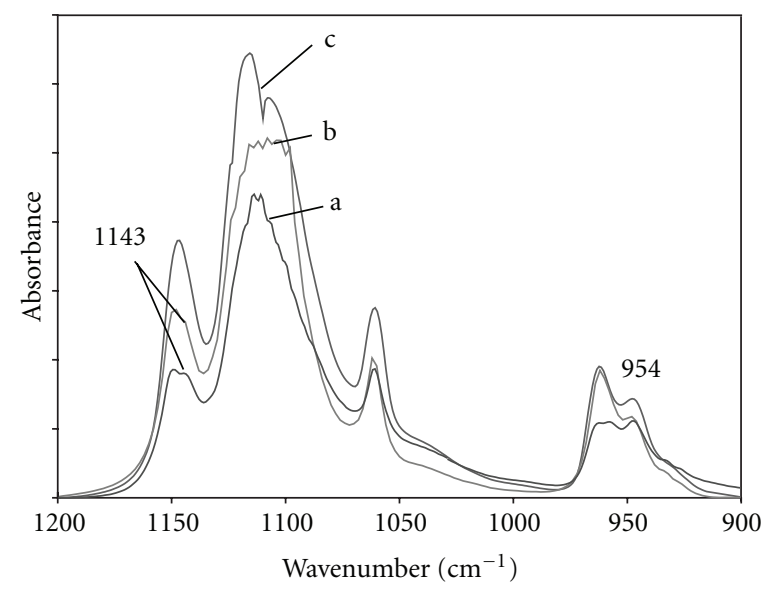

(A)

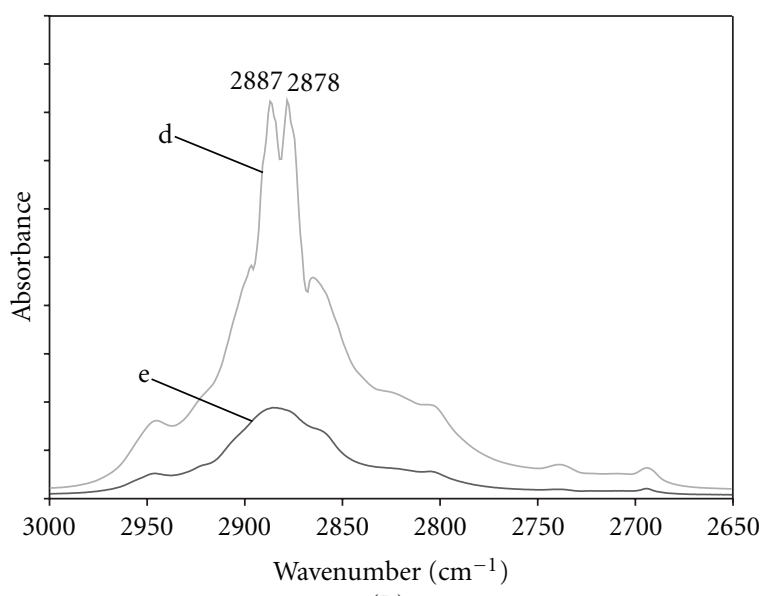

(B)

Figure 8: The $\mathrm{CO}$ and $\mathrm{CH}_{2}$ stretching bands in thick films in the process of aging Trace (a) Multipeak CO band in a $27 \mu \mathrm{m}$ film showing tracers of network at $1144 \mathrm{~cm}^{-1}$ and $956 \mathrm{~cm}^{-1}$ Trace (b) Multipeak CO band in a $30 \mu \mathrm{m}$ film with the same tracers at $1144 \mathrm{~cm}^{-1}$ and $956 \mathrm{~cm}^{-1}$. Trace (c) Double peak CO band in a $45 \mu \mathrm{m}$ film. The $1144 \mathrm{~cm}^{-1}$ and $956 \mathrm{~cm}^{-1}$ bands are not apparent at that stage. Trace (d) Multipeak in the $\mathrm{CH}_{2}$ stretching band $(56 \mu \mathrm{m})$. The films are aged three days except b, aged one week. For comparison, the $\mathrm{CH}_{2}$ stretching band of a $15 \mu \mathrm{m}$ film after the temperature treatment (Therm- $\mathrm{T})$ is given in the trace (e).

regions takes place concomitantly with the formation of stress in other regions. Relaxation is registered around the frequency of the vibration of the CO stretching, but with a different pattern, which overlaps the frequency due to the strain. One cannot separate the contributions of tension and relaxation on the IR spectra. Consequently, the vibrational spectra are complex and their overall shape changes with temperature, with alternation of sharp bands and wider bands. The sharper absorptions seen at slightly different positions at 36 and $60^{\circ} \mathrm{C}$ in Figure 3 are not unique to these temperatures, neither are the wider peaks observed at 42,54 , $72^{\circ} \mathrm{C}$. The same spectra measured at $48,68,78$ and $84^{\circ} \mathrm{C}$ (not shown) display also a combination of sharp and wider bands. The new bands are still present above $61^{\circ} \mathrm{C}$, the value of $T_{m}$ observed in standard calorimetry. At $84^{\circ} \mathrm{C}$, well above $T_{m}$ and $6 \mathrm{~K}$ below the maximum temperature, the intensity of the signal is reduced as is the rate of the temperature increase programmed by the temperature control. The IR spectrum at $T=60^{\circ} \mathrm{C}$ will be further discussed below, in relation to the presence of indicators of interchain interactions.

3.4. The $C-C-O$ Bending Region between $650-500 \mathrm{~cm}^{-1}$ as a Function of $T$. Figures 4(a) and 4(b) give the trace in the $650-500 \mathrm{~cm}^{-1}$ region. The trace $\mathrm{a}$ is in the melt at the maximum of deformation $\left(90^{\circ} \mathrm{C}\right)$, trace $\mathrm{b}$ is in the descending T-ramp. The two traces are constituted of a large flat peak between 600 and $510 \mathrm{~cm}^{-1}$ and of a region between 510 and $500 \mathrm{~cm}^{-1}$ which is different for the two temperatures. In highly deformed and crystalline samples [12], a doublet is observed at $529-508 \mathrm{~cm}^{-1}$ instead of the flat peak observed in Therm-T. The doublet intensity changes greatly with orientation [12]. It is attributed to a $\mathrm{C}-\mathrm{C}-\mathrm{O}$ bending mode. In the present nonoriented sample, the doublet appears as a group 
of peaks whose maximum intensity change with temperature and tension on the sample. There is not a unique way to trace the variation of this region with temperature. The nonstandard integrated absorbance has been chosen with limits between 650 and $500 \mathrm{~cm}^{-1}$. The integration is between the trace and a horizontal base line with an ordinate at 0.04 . The values of the integrated absorbance as a function of temperature are reported in Figure 5.

The integrated absorbance increases from 4 to $7.5 \mathrm{~cm}^{-1}$ as the temperature is raised from $30^{\circ} \mathrm{C}$ to $90^{\circ} \mathrm{C}$. This increase is associated with an accumulation of deformations of the C$\mathrm{C}-\mathrm{O}$ bonds during the rise of $\mathrm{T}(\bigcirc)$. When T decreases $(\square)$, the intensity of the vibration mode is reduced as displayed in the figure. There are interesting differences of response to the deformation between the $\mathrm{C}-\mathrm{C}$ twisting band absorption (Figure 3 ) and the $\mathrm{C}-\mathrm{C}-\mathrm{O}$ bending regions (Figure 4 ). The new bands at $1096 \mathrm{~cm}^{-1}$ in Figure 3 appear at the beginning of the ramp $\left(36^{\circ} \mathrm{C}\right)$, while the intensity of the $\mathrm{C}-\mathrm{C}-\mathrm{O}$ bending mode in Figure 5 is still small at $54^{\circ} \mathrm{C}$. The increase of the ordinate of Figure 5 in the T-ramp is 4.2 . Part of the deformation takes place below and at $T_{m}$ (2.5) and part in the melt (1.7).

The nature of the atoms involved in the two types of vibration is probably at the origin of the difference in the onset of the signal. In the $\mathrm{C}-\mathrm{C}$ twisting bands, the change which takes place between 1100 and $1090 \mathrm{~cm}^{-1}$ involves two (or possibly three) atoms in the chain. The T-ramp induces an immediate response such as a change of angle between adjacent bonds due to rotation. A different movement associated with relaxation following strain takes place a few $\mathrm{K}$ higher and leads to a shift of the signal (less than $5 \mathrm{~cm}^{-1}$ ). The successive events do not seem to be additive. On the other hand, the signal of the $\mathrm{C}-\mathrm{C}-\mathrm{O}$ bending mode $(650$ and $500 \mathrm{~cm}^{-1}$ ) which is spread over $150 \mathrm{~cm}^{-1}$ involves three or more atoms in the chains. The IR spectroscopic response is delayed by $30 \mathrm{~K}$ (or $60 \mathrm{~min}$ ), until there is enough mobility in the material for the chains to move cooperatively. The changes which are additive become larger as the maximum temperature are reached. The deformation in the $\mathrm{C}-\mathrm{C}-\mathrm{O}$ bending mode is reversible $(\square)$ in the conditions of the T-ramp. The intensity decreases on cooling and reaches a value of $4.5 \mathrm{~cm}^{-1}$ which is somewhat higher than that at the beginning of the ramp $\left(3.8 \mathrm{~cm}^{-1}\right)$. Suggesting a memory of the treatment. The integrated absorbance data reported in Figure 5 include deformation and relaxation.

The exact values of the integrated absorbance reported in Figure 5 and their variation with temperature depend on the position of the base line. Others integration while being less direct than the one explained above give similar trends.

3.5. Other Events in the Melt. The intensity changes only slightly but consistently in the melt between $T_{m}$ and $90^{\circ} \mathrm{C}$. The intensity of the $-\mathrm{CH}_{2}$ wagging and twisting vibrations between 1400 and $1200 \mathrm{~cm}^{-1}$ decreases by $5 \%$ in the ascending ramp but regains on cooling exactly the same value. The intensity of the $-\mathrm{CH}_{2}$ rocking band decreases and regains $7 \%$ in the same $\mathrm{T}$ ramp. These variations parallel those of the heat flow observed by calorimetry in the melt during a slow T-ramp (Appendix).
3.6. Films at RT: Differences between Therm-T and Reference. A comparison was made between Therm-T (after the temperature cycle) and a solution-grown film called Reference, in order to locate a possible remnant at RT of the effect of the ramp on the morphology. The reference has been prepared in conditions chosen to minimize the stress as reported in the experimental part. The absorbance of the doublets at 1359/ $1343,1242 / 1234$, and $963 / 947$ indicate that the films have the same fraction of $\|$ and $\perp$ orientations.

3.7. Thin Films. Some differences are seen in the 1200$900 \mathrm{~cm}^{-1}$ region for these two thin films. The non-differenciated absorbance (NDA) is larger in Therm-T than in Reference. The difference between the positions of the baseline at $1200 \mathrm{~cm}^{-1}$ and $970 \mathrm{~cm}^{-1}$ is larger for Therm-T (solid line) than for Reference (dotted line). In the CO band, Therm$\mathrm{T}$ has a large shoulder at $1109 \mathrm{~cm}^{-1}$ close to the band at $1114 \mathrm{~cm}^{-1}$. Reference has a maximum at $1111.8 \mathrm{~cm}^{-1}$ and no apparent shoulder is observed at lower frequency. A parallel band has been calculated and found experimentally at $1103 \mathrm{~cm}^{-1}[11,12]$. The increase of the parallel band which displaces the band towards low frequency in Therm- $T$ is assigned to chain-chain interactions.

This shift from helical to transplanar zigzag conformation takes place when chains interact, as observed repeatedly in PEO ions systems and in composites [34]. Small bands at $1144 \mathrm{~cm}^{-1}$ and at $956 \mathrm{~cm}^{-1}$ (between the two peaks at 963 and $947 \mathrm{~cm}^{-1}$ ) are well seen in Therm-T (Figure 6), but it is not obvious in Reference (Figure 6). These bands are of interest as potential indicators of a specific network organization as discussed below.

3.8. Indicators of the Network Organization and Effect of Aging. In order to confirm the assignment of the $1144 \mathrm{~cm}^{-1}$ and the $956 \mathrm{~cm}^{-1}$ band to a network organization, films were prepared in conditions where the network fraction was likely to be either important or small. The strategies to prepare a network-rich film are diverse: using a solution of a high MW, or a semiconcentrated solution, or stirring vigorously during dissolution, or annealing the melt in specific conditions. Thin and thick films have been prepared in network-forming conditions, such as films obtained from gels, films obtained from melts left standing at $90^{\circ} \mathrm{C}$, films made from $3 \%$, and $4 \%$ solution and films prepared from a high molecular weight sample. The $1144 \mathrm{~cm}^{-1}$ and $956 \mathrm{~cm}^{-1}$ bands are seen in all these films. The IR spectra of two of them are shown in Figures 7(a) and 7(b). The film whose spectrum is shown in Figure $7(\mathrm{a})$ is $2.3 \mu \mathrm{m}$ thick and was prepared from a gel. The two bands at 1144 and $956 \mathrm{~cm}^{-1}$ are present. Figure $7(\mathrm{~b})$ is Therm- $\mathrm{T}$ at $60^{\circ} \mathrm{C}$ (presented already in Figures 2(a) and 2 (b) on a narrow interval of frequencies). The spectrum at that temperature has interesting features in relation to the network bands. The crystalline band at $1149 \mathrm{~cm}^{-1}$ (at $60^{\circ} \mathrm{C}$ ) is reduced, so that it forms with the network band at $1144 \mathrm{~cm}^{-1}$ almost a flat peak. This is also the case for the $956 \mathrm{~cm}^{-1}$ band (between the bands at 963 and $946 \mathrm{~cm}^{-1}$ ) which has disappeared. The deformation peak at $1096 \mathrm{~cm}^{-1}$, 
seen in Figure 3, is quite intense at that temperature. The presence of the network bands in Therm-T $(15 \mu \mathrm{m})$ leads to the reconsideration of the limit of thickness. Therm- $\mathrm{T}$ is probably at the limit between thin and thick films.

3.9. Decomposition of the Bands. Decomposition of the bands was done on the $963-947 \mathrm{~cm}^{-1}$ doublet for Reference (Figure 6) and the film from the gel (Figure 7(a)). In the film not enriched in network, the fraction at $956 \mathrm{~cm}^{-1}$ of the total peak is found to be 0.14 , while it is 0.33 for the film made from a gel. The film from the gel has a higher fraction of parallel band at $963 \mathrm{~cm}^{-1}$ seen on the spectra and in the decomposition. However, this does not seem to displace the network band, since in other films prepared in networkenriching conditions and where the parallel and perpendicular fraction have the same magnitude, the decomposition leads also to a higher fraction of the $956 \mathrm{~cm}^{-1}$ band.

3.10. Thicker Films. The analysis of thicker films leads to the finding that their spectra change with time and that even those prepared in dilute solution reach, after some time (days and weeks), the profile of thin films prepared in networkforming conditions.

Four spectra are given as examples of the effect of thickness and aging on the $\mathrm{CO}$ and the $\mathrm{CH}_{2}$ stretching band.

3.10.1. CO Band. The film of $27 \mu \mathrm{m}$ whose spectrum is shown in Figure 8(a) has been prepared by cooling a melt annealed at $90^{\circ} \mathrm{C}$ and is aged for three days. The bands associated with a network are seen at $1144 \mathrm{~cm}^{-1}$ and $956 \mathrm{~cm}^{-1}$. The CO peak is multipeak $\left(1114 \mathrm{~cm}^{-1}, 1110 \mathrm{~cm}^{-1}\right)$ with small shoulders at $1106 \mathrm{~cm}^{-1}$ and at a lower wavenumber. The spectrum of the $30 \mu \mathrm{m}$ film of Figure 8 (b) has been aged during one week and shows also the $1144 \mathrm{~cm}^{-1}$ and $956 \mathrm{~cm}^{-1}$ bands. The spectrum of the $45 \mu \mathrm{m}$ film of Figure 8 (c) has been aged during three days. The $1144 \mathrm{~cm}^{-1}$ and $956 \mathrm{~cm}^{-1}$ bands are not apparent at that stage. The maximum absorbance of the CO peak is higher than after one day of aging, two maxima are seen at $1115.6 \mathrm{~cm}^{-1}$ and $1107.5 \mathrm{~cm}^{-1}$. After a longer aging, the spectrum of that film (or of others with the same history) will develop towards that of Therm-T.

3.10.2. $\mathrm{CH}_{2}$ Stretching Band. The trace in Figure $8(\mathrm{~d})$ is that of a $56 \mu \mathrm{m}$ film, aged three days. The maximum absorbance of the $\mathrm{CH}_{2}$ stretching region is high in relation with its thickness with two thin peaks at 2887 and $2878 \mathrm{~cm}^{-1}$. The maximum absorbance diminish after a longer aging and the two peaks are replaced by one situated in between the previous peaks, at $2883 \mathrm{~cm}^{-1}$, with a shoulder at $2866 \mathrm{~cm}^{-1}$ (Figure 1(a)).

It is worth noting that a relatively small difference in thickness (from 5 to $15 \mu \mathrm{m}$ for instance) increases sufficiently, in thicker films, the time during which the chains have enough mobility to reach an organization different from that of thin films prepared in the same conditions. When chains must move to let favourable interactions between the oxygen and hydrogen atoms to form, it is not unexpected that equilibrium be slow after the initial temporary organization which takes place during drying. In thin films prepared in network-forming conditions, the network is already in place in the solution so that the time in the drying phase is not determining. Slow movements of the chains have been observed in polystyrene by different techniques [41].

The importance of film thickness and time of measurement on the shape and height of the complex CO peak explains the difficulty in finding a reliable extinction coefficient of this region by measuring films of different thickness at about the same time of aging [35]. The crystalline bands of medium intensity such as that at $1280,1060,842 \mathrm{~cm}^{-1}$ have been reported to be little sensitive to conformational order [34] so they change little during aging in films of different thickness.

The $\mathrm{C}-\mathrm{C}$ bonds are somewhat deformed to form the cooperative association between the oxygen and hydrogen atoms. Deformation of chain entangled in a network will be different from that of less entangled chains. In the 650$500 \mathrm{~cm}^{-1}$ region, deformation as measured from the integrated absorbance increases with $\mathrm{T}$ but is significant at RT. The difference between the value of the integrated absorbance of Therm-T in Figure 6 at RT (4.5) and that of Reference (2.8) can count also as an indicator of network. The spectra of Therm-T display irregularities while that of Reference is smoother. Both have a peak at $530 \mathrm{~cm}^{-1}$.

Solutions have been prepared with the sample with $\mathrm{MW}=$ $10^{6}$. The dissolution is made at $40^{\circ} \mathrm{C}$ with a magnetic stirrer and evaporation takes place at RT. The spectra of the films made with a higher MW are somewhat more turbid than those prepared with the $\mathrm{MW}=10^{5}$ sample. The tracers of network, the bands at 1144 and $956 \mathrm{~cm}^{-1}$ are well seen on these films. As the spectra were comparable to those made from concentrated solutions of $\mathrm{MW}=10^{5}$, the spectra of these films have not been presented in the present work.

3.11. PEO and PE Extinction Coefficients. The measure of $\varepsilon$ through the analyses of films of different thickness is not as straightforward for the large bands as it is in PE films due to the slow maturing of thicker films as remarked above. One can however make some comparison for thin films prepared in dilute solution which have reached in equilibrium. The ratio $\varepsilon(\mathrm{PE}) / \varepsilon(\mathrm{PEO})$ has been measured $[29,30,35-40]$ for different regions. The two extremes of this ratio are the $\mathrm{CH}_{2}$ stretching (2.2) and gauche (0.076). The well-ordered chains of the orthorhombic crystals of PE lead to a high value of ratio $\mathcal{E}(\mathrm{PE})$ and of the ratio $\mathcal{\varepsilon}(\mathrm{PE}) / \mathcal{E}(\mathrm{PEO})$. On the other hand, due to the helical conformation of the PEO chains and the zigzag morphology of $\mathrm{PE}, \varepsilon_{\text {gauche }} \mathrm{PEO}$ ) is high and the ratio ratio $\mathcal{E}(\mathrm{PE}) / \mathcal{E}(\mathrm{PEO})$ is low. The ratio for the rocking and bending are intermediary (0.71) and (1.40). The rocking and bending are composites with different composition of $\mathrm{CH}_{2}$ and $\mathrm{CO}$ vibrations which explain the variability of this ratio.

\section{Conclusion}

Spectra of PEO placed between KBr plaques have been obtained during melting and crystallization in a slow T-ramp. Finding IR indicators of the change of morphology between 
the solid and the melt, of strain building and of network organization, were the aims of this investigation. The spectra of free standing films with different history are compared to those of the treated film.

In PE, melting leads to the disappearance of the doublets whose origin was the dense orthorhombic crystals. In PEO, the doublets associated with perpendicular and parallel bands, are replaced above $T_{m}$ by smaller bands, other crystalline bands have their intensity reduced. The integrated absorbance of the largest bands, that of the $\mathrm{CH}_{2}$ stretching and that of the complex $\mathrm{CO}$ band on the other hand, remains at the same value in the melt while their position and width change. The change of order at melting as seen by the IR spectra is large for PE and small in part for PEO because solid PEO seems already quite disordered. At $T_{m}$, the density of PE is reduced by $20 \%$ while it diminishes by only a few percent in PEO.

Several indicators of tension are found on the spectra taken at different temperatures. New peaks at 1090$1096 \mathrm{~cm}^{-1}$ in the vicinity of the maximum of the complex CO develop as soon as the T-ramp starts. They persist in the melt until the maximum temperature reached. Stretching and relaxation occur simultaneously or in turn during the ramp as seen on the calorimetric trace (Appendix). Another region sensitive to strain is the $\mathrm{C}-\mathrm{C}-\mathrm{O}$ bending region (650 and $500 \mathrm{~cm}^{-1}$ ). The variation of the integrated absorbance parallels the T-ramp. It increases in the solid and the melt in the ascending ramp and decreases in the descending ramp.

Films prepared using network enriching conditions (solutions of high MW or of a higher concentration) were compared with other films. Two small bands at $1144 \mathrm{~cm}^{-1}$ and $956 \mathrm{~cm}^{-1}$, found in films prepared from network enriched solutions and in Therm-T, are associated with chains in a network. In thin films prepared from dilute solutions these indicators of network are less apparent. This suggests that with enough time, cooperative associations between the oxygen and hydrogen atoms lead to the formation, during the drying and aging process, of a stable network. In thin films which solidify fast, the network is more fragmented and incomplete. A parallel band at low wavenumber in the complex CO peak increases when a chain interacts with another chain in a composite [34] or with an ion. A similar displacement takes place for autoassociation between PEO chains.

The spectra of thick films $(20 \mu \mathrm{m})$ have been followed during their maturing. The complex $\mathrm{CO}$ band and the $\mathrm{CH}_{2}$ stretching regions for instance are seen to change greatly in band intensity and position before reaching equilibrium where the indicators of network are found.

An example of a trace of melting in a slow T-ramp is given in the appendix. Besides the main endotherm of melting, other events associated with deformation/relaxation are observed.

The trace shows the main endotherm peak as expected when the crystals of PEO melt. Between RT and $60^{\circ} \mathrm{C}$, an endothermic flat peak is interpreted as the absorption of heat when the sample is stretched in the T-ramp. Other endothermic peaks between 95 and 105 and 118 and $122^{\circ} \mathrm{C}$ have the same origin. The exothermic peak between 105 and $115^{\circ} \mathrm{C}$

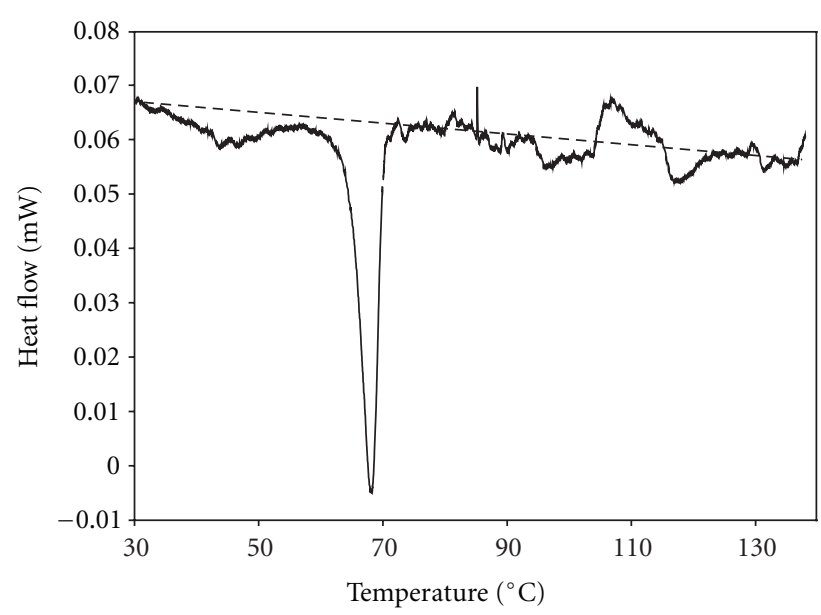

Figure 9: Melting trace of $\mathrm{PEO}$ in a $0.05 \mathrm{~K} / \mathrm{min}$ ramp between 28 and $140^{\circ} \mathrm{C}$. Endotherms and exotherms associated with chain deformation and relaxation accompany the main peak of fusion.

is associated with the relaxation of stretched chains. The sequence of deformation/relaxation is dependant on the conditions of the T-ramp. The observation of these events in a standard DSC calorimeter using a $1 \mathrm{~K} / \mathrm{min}$ ramp was possible in specific conditions, namely, a small mass $(0.2 \mathrm{mg})$ and an open cell to avoid restraint on the sample [27].

\section{Appendix}

Calorimetric Trace in a Slow T-Ramp (0.05 K/Min). The trace of melting shown as Figure 9 has special features compared to the standard melting trace. $T_{m}$ is displaced at higher $\mathrm{T}$ $\left(68^{\circ} \mathrm{C}\right.$ instead of $\left.61^{\circ} \mathrm{C}\right)$ and with $\Delta \mathrm{H}_{\mathrm{m}}=130 \mathrm{~J} / \mathrm{g}$. Endotherms and exotherms are seen on the trace. The first endotherm between $30^{\circ} \mathrm{C}$ and $58^{\circ} \mathrm{C}$ corresponds to the deformation of the sample $(33 \mathrm{~J} / \mathrm{g})$. Above $T_{m}$, between $72^{\circ} \mathrm{C}$ and $104^{\circ} \mathrm{C}$, deformation and relaxation overlap $(27 \mathrm{~J} / \mathrm{g})$. A peak of relaxation follows with a maximum at $107^{\circ} \mathrm{C}(-36 \mathrm{~J} / \mathrm{g})$. Another peak of deformation has a maximum at about $115^{\circ} \mathrm{C}(14 \mathrm{~J} / \mathrm{g})$. In the slow ramp, a fraction of the entangled chains in a crystalline organization is subject to a continuous stress. The melting of the strained crystals does not take place but at a higher T. Consequently, the value of $\Delta \mathrm{H}_{\mathrm{m}}$ of the main peak is reduced of about $10 \%(130 \mathrm{~J} / \mathrm{g})$ compared to the standard DSC value $(147 \mathrm{~J} / \mathrm{g})$.

Conditions: $0.05 \mathrm{~K} / \mathrm{min}$ between 28 and $140^{\circ} \mathrm{C}, \mathrm{m}=$ $2.38 \mathrm{mg}$. Sample placed on $\mathrm{Hg}$ in a glass tube. The glass is sealed under vacuum.

The Growth of Tension in a T-Ramp: from Calorimetry to FTIR. The heat of dissolution $\Delta \mathrm{H}_{\text {diss }}$ of UHMWPE in different nonpolar solvents was measured in order to understand gel formation. Because of the slow kinetics of dissolution, the rate of heating $v$ was reduced until a homogenous gel was obtained in the revolving calorimeter. $\Delta \mathrm{H}_{\text {diss }}$ was found to vary with the solvent; an unexpected result since in nonpolar solvents, $\Delta \mathrm{H}_{\text {diss }}$ is due almost entirely to the heat of fusion of 
orthorhombic crystals. With $\nu=0.05 \mathrm{~K} / \mathrm{min}$ or less, a second endotherm, $\Delta \mathrm{H}_{\text {high-T }}$ was observed. An experiment in the same condition but without solvent lead to traces showing the same calorimetric features as those found to study the gels.

In the slow T-ramp, deformation of the sample is followed, at higher $\mathrm{T}$, by relaxation. The time interval between the successive movements of the chains in the noncrystalline regions and in the melt is large, of the order of hours rather than minutes. The slow T-ramp of the calorimeter is suited to follow these events. Such slow motions have been observed recently by neutron scattering and imaging on polystyrene over a range of temperature [41]. One of the conclusions of the investigation was that orientation at the length scale of the entire chain decays considerably more slowly than at the smaller entanglement length. The findings of the PS were instrumental in interpreting the events in the melt PE taking place during a slow T-ramp. Thermal events in the melt were found a general occurrence in polyolefins and other polymers when melting took place in a low T-ramp using condition similar to those in the C80 calorimeter. The relaxation with a rapid kinetics is observed easily while deformation is continuous and sometimes overlaps the base line or the beginning of melting.

By changing dramatically the conditions of melting, events different from the melting of long-range order could be observed [27]. Measurements were made with a standard DSC $(v=1 \mathrm{~K} / \mathrm{min})$ with a small mass to increase heat transfer $(0.5-1.5 \mathrm{mg})$ and an open cell to avoid restraint of chain motion. In these DSC experiments, the large unambiguous values of $\Delta \mathrm{H}_{\text {low- }}$ and $\Delta \mathrm{H}_{\text {high-T }}$ were too large to sustain completely our first interpretation [18-22] of the events which stood like this: the slow ramp generates strain in crystals whose melting point is above the value of $T_{m}$ of nonstrained crystals. The two effects described above complete each other.

Looking for IR indicators of deformation/relaxation in a slow T-ramp was the obvious step to follow after the calorimetric study. The changing shape of the bands between 1090 and $1100 \mathrm{~cm}^{-1}$ and between $650-400 \mathrm{~cm}^{-1}$ found in this work are seen as indicators of slow deformation and slow relaxation of $\mathrm{PEO}$ chains. These events can take place in succession or simultaneously.

\section{Acknowledgments}

The support of the NSERC National Science and Engineering Research Council of Canada is appreciated. The contributions of Selenis Canada (PTT Poly Canada) for C. Bergeron and of the University of Clermont-Ferrand for A. Potier and E. Perrier and other students have been helpful.

\section{References}

[1] P. Lightfoot, M. A. Mehta, and P. G. Bruce, "Crystal structure of the polymer electrolyte poly(ethylene oxide) ${ }_{3}: \mathrm{LiCF}_{3} \mathrm{SO}_{3}$," Science, vol. 262, no. 5135, pp. 883-885, 1993.
[2] B. Wunderlich, Macromolecular Physics, vol. 3, Academic Press, London, UK, 1980.

[3] G. Strobl, The Physics of Polymers, Springer, Berlin, Germany, 1997.

[4] J. M. Schultz and M. J. Miles, "AFM study of morphological development during the melt-crystallization of poly(ethylene oxide)," Journal of Polymer Science B, vol. 36, no. 13, pp. 23112325, 1998.

[5] K. Dalnoki-Veress, J. A. Forrest, M. V. Massa, A. Pratt, and A. Williams, "Crystal growth rate in ultrathin films of poly(ethylene oxide)," Journal of Polymer Science B, vol. 39, no. 21, pp. 2615-2621, 2001.

[6] M. Polverari and T. G. M. Van De Ven, "Dilute aqueous poly (ethylene oxide) solutions: clusters and single molecules in thermodynamic equilibrium," Journal of Physical Chemistry, vol. 100, no. 32, pp. 13687-13695, 1996.

[7] D. L. Ho, B. Hammouda, and S. R. Kline, "Clustering of poly (ethylene oxide) in water revisited," Journal of Polymer Science B, vol. 41, no. 1, pp. 135-138, 2002.

[8] A. K. Khasanova and B. A. Wolf, "PEO/CHCl 3 . Crystallinity of the polymer and vapor pressure of the solvent. Equilibrium and nonequilibrium phenomena," Macromolecules, vol. 36, no. 17, pp. 6645-6652, 2003.

[9] M. Duval, "Monitoring of cluster formation and elimination in PEO solutions," Macromolecules, vol. 33, no. 21, pp. 78627867, 2000.

[10] M. Duval and F. Boué, "Dilute polyethylene oxide aqueous solutions in a turbulent flow," Macromolecules, vol. 40, no. 23, pp. 8384-8388, 2007.

[11] T. Miyazawa, K. Fukushima, and Y. Ideguchi, "Molecular vibrations and structure of high polymers. III. Polarized infrared spectra, normal vibrations, and helical conformation of polyethylene glycol," The Journal of Chemical Physics, vol. 37, no. 12 , pp. 2764-2776, 1962.

[12] H. Matsuura and T. Miyazawa, "Vibrational analysis of molten poly (ethylene glycol)," Journal of Polymer Science Part A-2, vol. 7, pp. 1735-1744, 1969.

[13] R. Frech, S. Chintapalli, P. G. Bruce, and C. A. Vincent, "Crystalline and amorphous phases in the poly(ethylene oxide)$\mathrm{LiCF}_{3} \mathrm{SO}_{3}$ system," Macromolecules, vol. 32, no. 3, pp. 808-813, 1999.

[14] Y. Geng, G. Wang, Y. Cong, L. Bai, L. Li, and C. Yang, "Surface adsorption-induced conformational ordering and crystallization of polyethylene oxide," Journal of Polymer Science B, vol. 48, no. 2, pp. 106-112, 2010.

[15] M. Spitzer, E. Sabadini, and W. Loh, "Entropically driven partitioning of ethylene oxide oligomers and polymers in aqueous/organic biphasic systems," Journal of Physical Chemistry B, vol. 106, no. 48, pp. 12448-12452, 2002.

[16] J. M. Harris, Polyethylene Glycol Chemistry, Biotechnical and Biomedical Applications, Plenum Press, New York, NY, USA, 1992.

[17] F. Gouanvé, H. Phuong-Nguyen, Z. F. Hamida, and G. Delmas, "A new technique to characterize mono-molecular micelles in random ethylene-propylene copolymers," Colloid and Polymer Science, vol. 283, no. 9, pp. 994-1006, 2005.

[18] H. Phuong-Nguyen, Melting Behaviour of Strained Crystals of Ultra High Molecular Weight Polyethylene with and without Solvent, Ph.D. thesis, McGill University, Montreal, Canada, 1990.

[19] H. Phuong-Nguyen and G. Delmas, "Arrested melting due to strain in ultrahigh molecular weight polyethylene," Macromolecules, vol. 25, no. 1, pp. 408-413, 1992. 
[20] H. Phuong-Nguyen and G. Delmas, "Thermal analysis and model of ultrahigh molecular weight polyethylene gels," Macromolecules, vol. 25, no. 1, pp. 414-421, 1992.

[21] G. Delmas, "Irreversible formation of a network during melting/dissolution of nascent PE," Journal of Polymer Science B, vol. 31, no. 13, pp. 2011-2018, 1993.

[22] H. Phuong-Nguyen and G. Delmas, "Information given by slow melting on phase content and maximum drawability of high molecular weight polyethylene films," Journal of Materials Science, vol. 29, no. 14, pp. 3612-3620, 1994.

[23] X. Zhang, H. Phuong-Nguyen, P. Bernazzani, I. Lapes, and G. Delmas, "Information on the noncrystalline phase of nascent iPP given by slow calorimetry," Canadian Journal of Chemistry, vol. 75, no. 10, pp. 1354-1362, 1997.

[24] H. Phuong-Nguyen and G. Delmas, "Crystallization of Isotactic Poly (propylene) in Solution as Followed by Slow Calorimetry," Collection of Czechoslovak Chemical Communications, vol. 60, pp. 1905-1924, 1995.

[25] H. Phuong-Nguyen, G. Charlet, and G. Delmas, "Slow calorimetry and heat of fusion of poly(4-methyl pentene-1)," Journal of Thermal Analysis, vol. 46, no. 3-4, pp. 809-832, 1996.

[26] Z. Ferhat-Hamida, H. Phuong-Nguyen, P. Bernazzani, A. Haine, and G. Delmas, "LLDPE's grown with metallocene and Ziegler-Natta catalysts: events in the melt and FTIR analysis," Journal of Materials Science, vol. 42, no. 9, pp. 3138-3154, 2007.

[27] I. Jedidi, Z. Ferhat-Hamida, and G. Delmas, "Calorimetry in nonstandard conditions: the noncrystalline phases of linear polyethylene," Journal of Polymer Science B, vol. 45, no. 15, pp. 1932-1949, 2007.

[28] P. Bernazzani, Contrôle de la morphologie des systèmes amyloseeau et caractérisation par DSC lent et FTIR, Ph.D. thesis, University of Quebec at Trois-Rivières, Trois-Rivières, Canada, 2000.

[29] P. Bernazzani, V. T. Bich, H. Phuong-Nguyen et al., "FTIR analysis of the phase content in lowdensity polyethylene," Canadian Journal of Chemistry, vol. 76, no. 11, pp. 1674-1687, 1998.

[30] P. Bernazzani, Analyse de la composition phasique du polyéthylène par FTIR: Mise en évidence d'une phase tendue, M.S. thesis, University of Quebec, Montreal, Canada, 1994.

[31] A. Ajji, J. Guèvremont, K. C. Cole, and M. M. Dumoulin, "Orientation and structure of drawn poly(ethylene terephthalate)," Polymer, vol. 37, no. 16, pp. 3707-3714, 1996.

[32] P. Bernazzani, C. Chapados, and G. Delmas, "Double-helical network in amylose as seen by slow calorimetry and FTIR," Journal of Polymer Science B, vol. 38, no. 12, pp. 1662-1677, 2000.

[33] P. Bernazzani, C. Chapados, and G. Delmas, "Phase change in amylose-water mixtures as seen by Fourier transform infrared," Biopolymers, vol. 58, no. 3, pp. 305-318, 2001.

[34] J. M. Marentette and G. R. Brown, "The crystallization of poly(ethylene oxide) in blends with neat and plasticized poly(vinyl chloride)," Polymer, vol. 39, no. 6-7, pp. 1415-1427, 1998.

[35] C. Bergeron, A. Potier, E. Perrier, and G. Delmas, Part 2 of this work, to be published.

[36] A. Potier, "Report 2002," University of Quebec at Montreal and IUT- University of Auvergne 2002.

[37] A. Pages, "Report 2007," University of Quebec at Montreal and IUT- University of Auvergne 2007.

[38] J. Morales, “Report 2005," University of Quebec at Montreal and IUT- University of Auvergne.
[39] E. Perrier, “Report 2003," University of Quebec at Montreal and IUT- University of Auvergne.

[40] A. Cohade, "Report 2003," University of Quebec at Montreal and IUT- University of Auvergne.

[41] J. Bent, L. R. Hutchings, R. W. Richards et al., "Neutron-mapping polymer flow: scattering, flow visualization, and molecular theory," Science, vol. 301, no. 5640, pp. 1691-1695, 2003. 


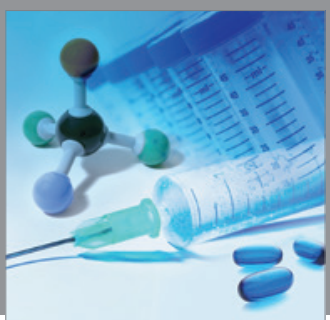

International Journal of

Medicinal Chemistry

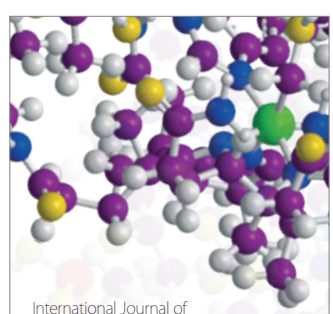

Carbohydrate Chemistry

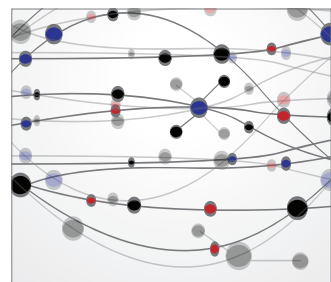

The Scientific World Journal
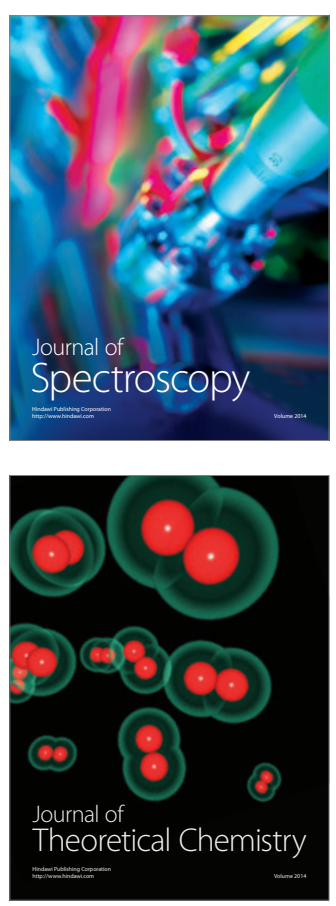


Submit your manuscripts at

http://www.hindawi.com
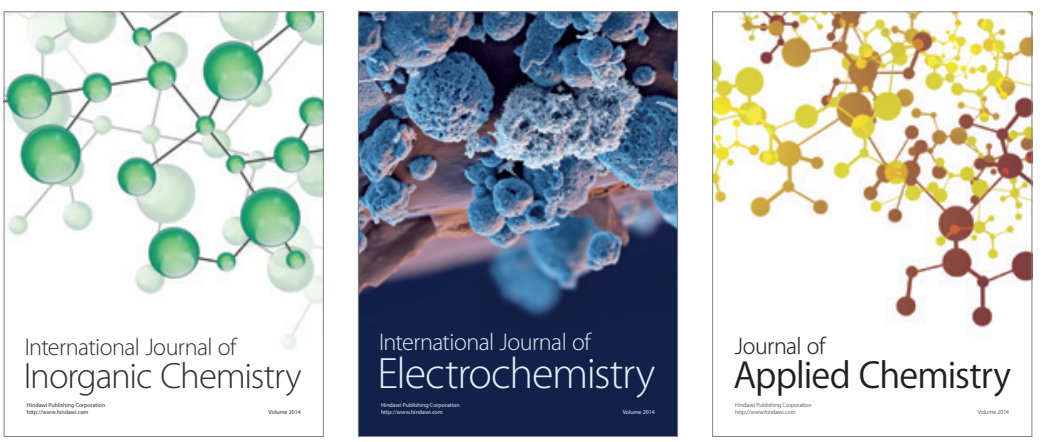

Journal of

Applied Chemistry
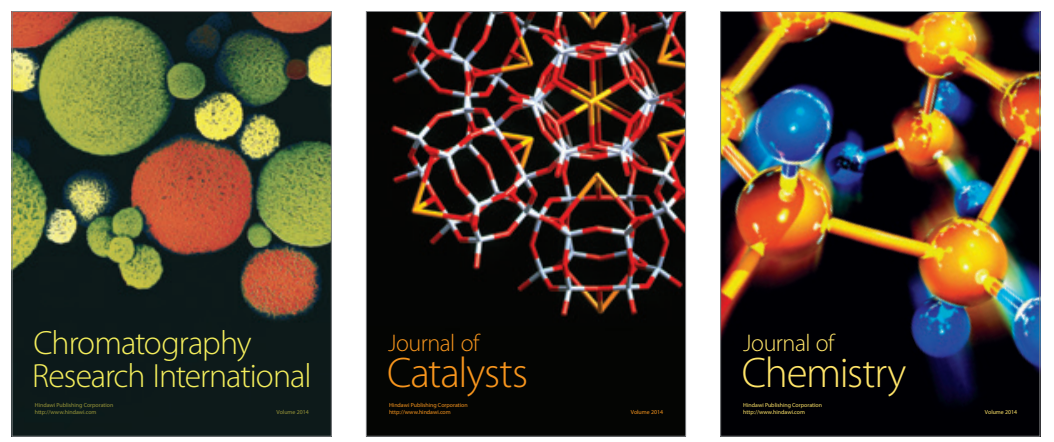
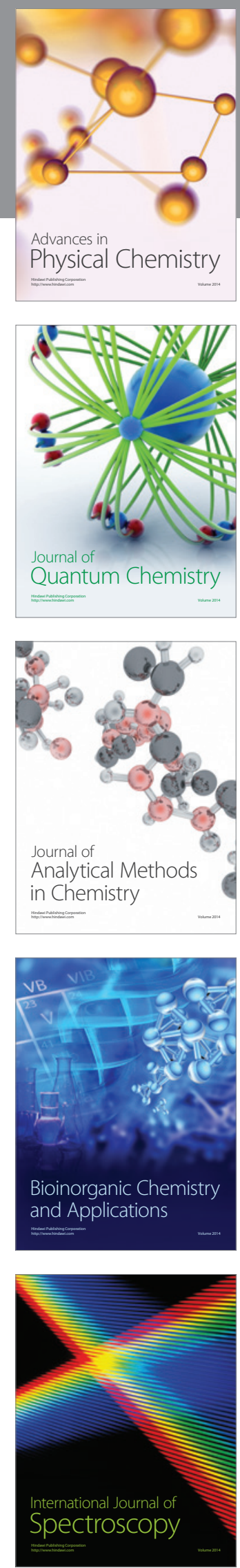